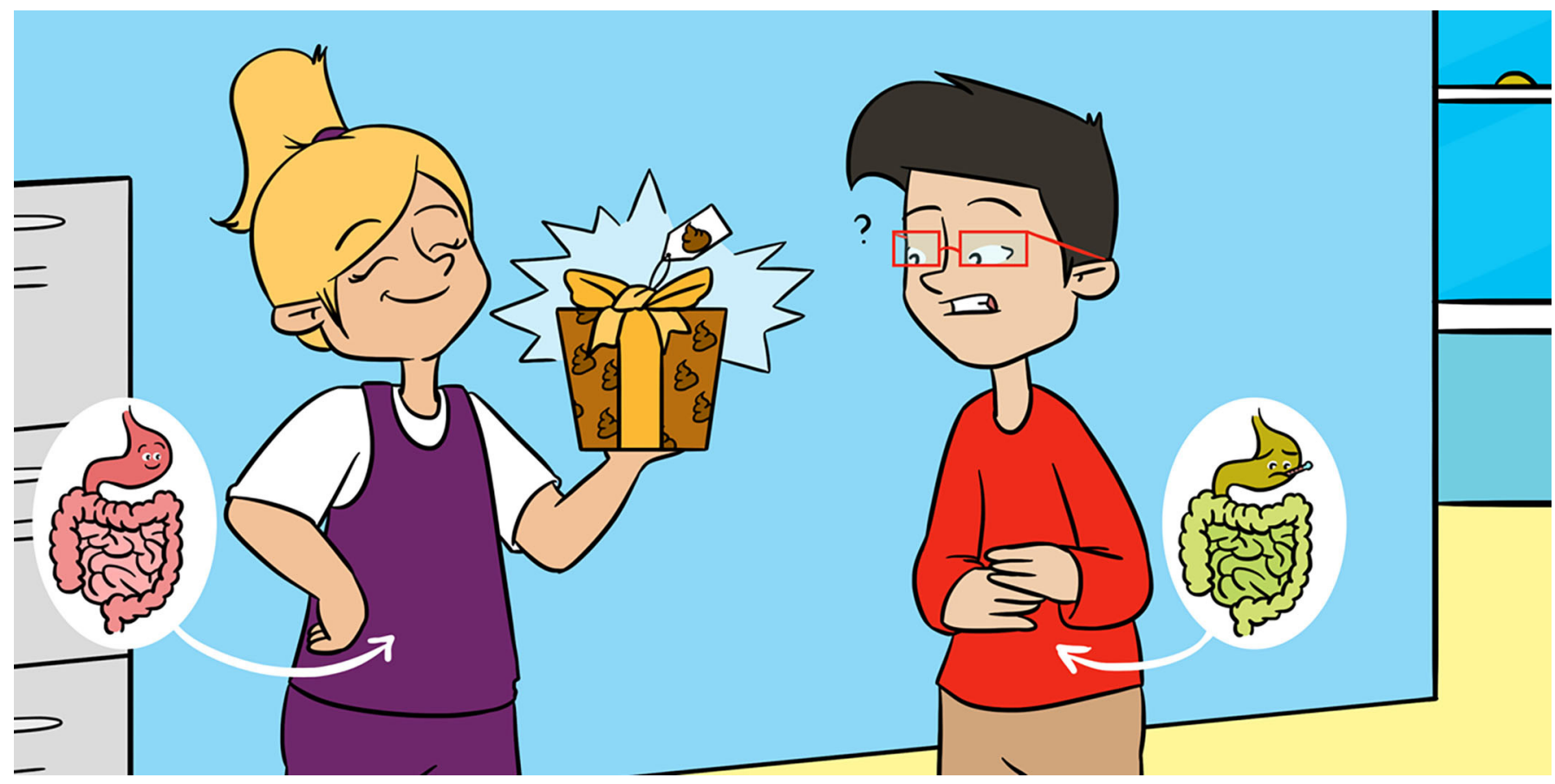

\title{
WHAT ARE POOP TRANSPLANTS AND HOW DO THEY WORK?
}

Sushmita Patwardhan ${ }^{1}$, Christian Diener ${ }^{1}$, Stephanie Swegle ${ }^{1}$, Becky Howsmon $^{1}$ and Sean M. Gibbons ${ }^{1,2,3^{*}}$

${ }^{1}$ Institute for Systems Biology, Seattle, WA, United States

${ }^{2}$ Department of Bioengineering, University of Washington, Seattle, WA, United States

${ }^{3}$ eScience Institute, University of Washington, Seattle, WA, United States

YOUNG REVIEWERS:

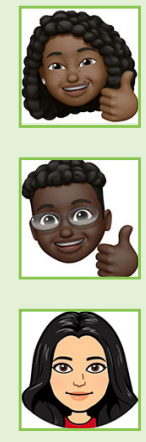

JADA

AGE: 14

JOSHUA

AGE: 14

REEYA

AGE: 15
Microbes are tiny creatures that live in and on our bodies. Many of them, especially those in the gut, help to keep us healthy. Sometimes, when we eat spoiled food or take antibiotics, we wipe out many of these good microbes. Usually, our good microbes recover from these disturbances, but sometimes harmful microbes can take their place and cause disease. Clostridioides difficile is a harmful microbe that causes severe diarrhea. Usually, antibiotics can kill $C$. difficile and return the gut to a healthy state, but in some cases, this microbe can come back again and again. Some people end up dying from these recurrent, antibiotic-resistant $C$. difficile infections. Recently, scientists have found that recurrent $C$. difficile can be cured by transplanting poop from a healthy person into a sick person. This process is called fecal microbiota transplantation (FMT) and it saves thousands of lives in the U.S. each year. 


\section{Figure 1}

More than half of the cells in and on our bodies are microbial and they account for $1 / 2-1$ pound of our body weight. These microbes can be found all over the exposed surfaces of our bodies, with most of them inside the gut.

\section{MICROBE}

A microscopic organism.

\section{MICROBIOTA}

All the microbes that live in and on your body.

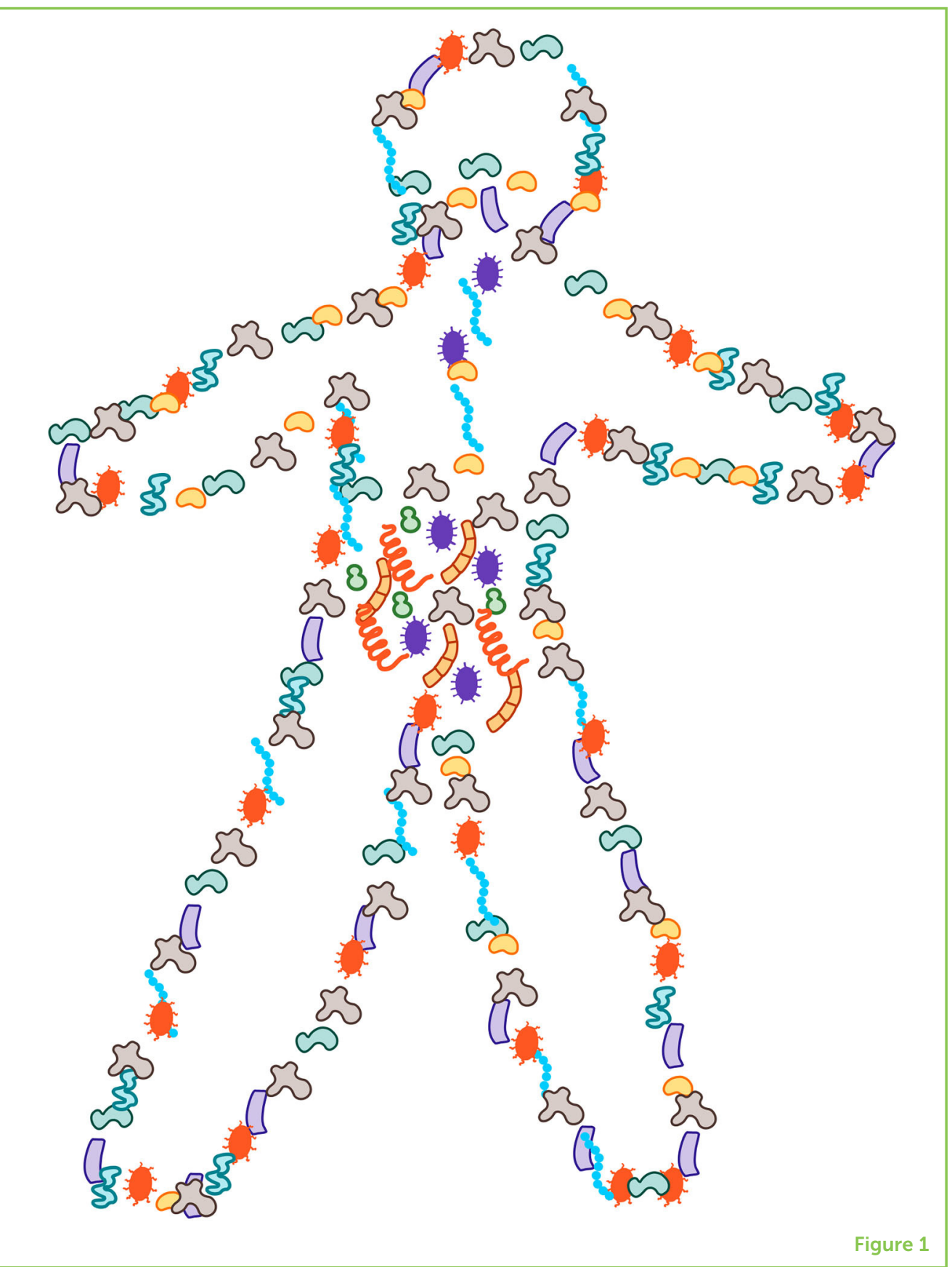

\section{MICROBES-FRIENDS NOT ENEMIES!}

You may have heard of microbes, or maybe you have heard them referred to as "germs" or "bugs." Despite these rather scary terms that remind us of disease, many of these organisms are actually good for you and play an important role in keeping you healthy. Although you cannot see these tiny creatures with your eyes, they are present all around you-in the air, on the wall, in the soil, and in and on your body (Figure 1). The vast majority of microbes are harmless or even beneficial. They consist of bacteria, archaea, protists, fungi, and viruses, collectively known as your microbiota, which outnumber the 
Figure 2

The gut is an

ecosystem, like a forest or a coral reef. Often, a disturbed ecosystem,

like a forest after a fire

(A) or the gut

microbiota after

antibiotic treatment (B),

recovers back to a

healthy state.

Occasionally, however, weedy species (such as C. difficile in the gut) can invade and take over after a disturbance, leading to a collapse of the normal ecology of the system.

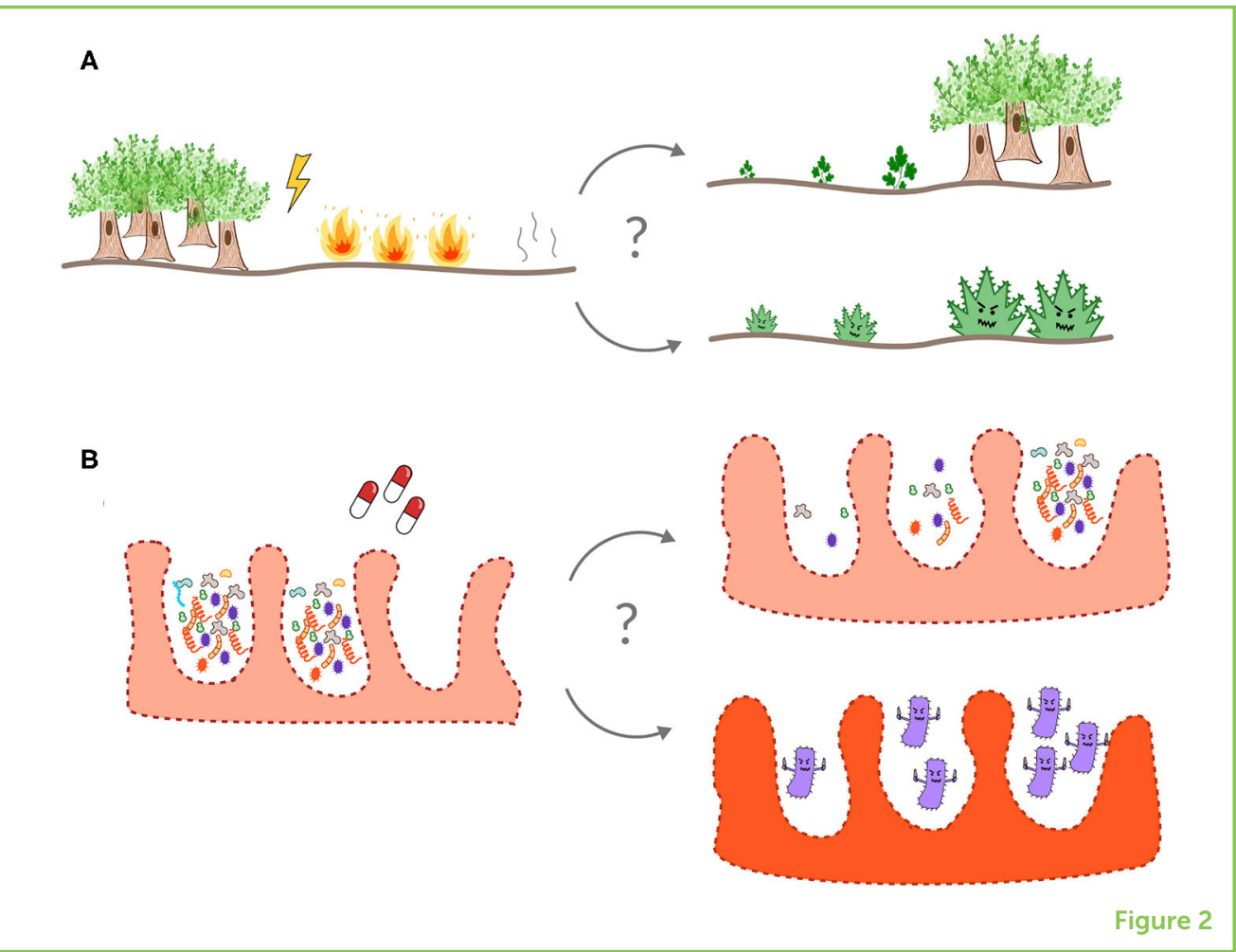

human cells in our bodies and make up between $1 / 2$ and 1 pound of your body weight.

We start out microbe-free in the womb [1], and begin to collect our microbiota at birth [2]. Humans are seeded with microbes from their moms and from their surrounding environments following birth. Over the course of a lifetime, we are colonized by different varieties of microbes depending on what foods we eat, where we live, how much we exercise, even whether or not we have a cat or a dog [2]. Thus, our bodies are complex ecosystems. We give our microbiota a home and in return they help to keep us safe and healthy.

The gut is where most of our microbiota live. And the most abundant component of the gut microbiota are the bacteria. Gut bacteria help us digest our food, absorb vitamins and nutrients, protect our bodies from harmful microbes known as pathogens, and train our immune systems to prevent allergies, asthma, and other immune dysfunctions. Gut bacteria can even send signals to our brains, altering our moods and behaviors [3]. We need a balance of the right kinds of bacteria in our guts to stay healthy.

\section{HEALTHY VS. UNHEALTHY MICROBIOTA}

What is a healthy gut microbiota? Each person has a unique microbiota and there is no one-size-fits-all definition for what comprises a healthy gut ecosystem [4]. Even if we do not know exactly what a healthy 
Figure 3

(A) Usually, the gut microbiota can recover from antibiotics.

(B) However, sometimes a pathogen like C. difficile can invade a damaged gut ecosystem. Usually, another dose of antibiotics can return the gut back to health. (C) Occasionally, C. difficile comes back again and again after antibiotics and becomes a recurring infection. Recurrent $C$. difficile causes thousands of deaths in the United States each year. (D) The most effective cure for recurrent $C$. difficile is a fecal microbiota transplant (FMT) from a healthy poop donor, otherwise known as a poop transplant.

\section{ANTIBIOTICS}

Medicines that kill or inhibit the growth of bacteria.

\section{CLOSTRIDIOIDES DIFFICILE}

An opportunistic bacterial pathogen that causes severe diarrhea in nearly 500,000 people and is responsible for over 10,000 deaths each year in the U.S.

\section{OPPORTUNISTIC PATHOGEN}

A microbe that is usually harmless but can cause disease when the immune system is depleted or when the normal ecology of the microbiota is damaged.

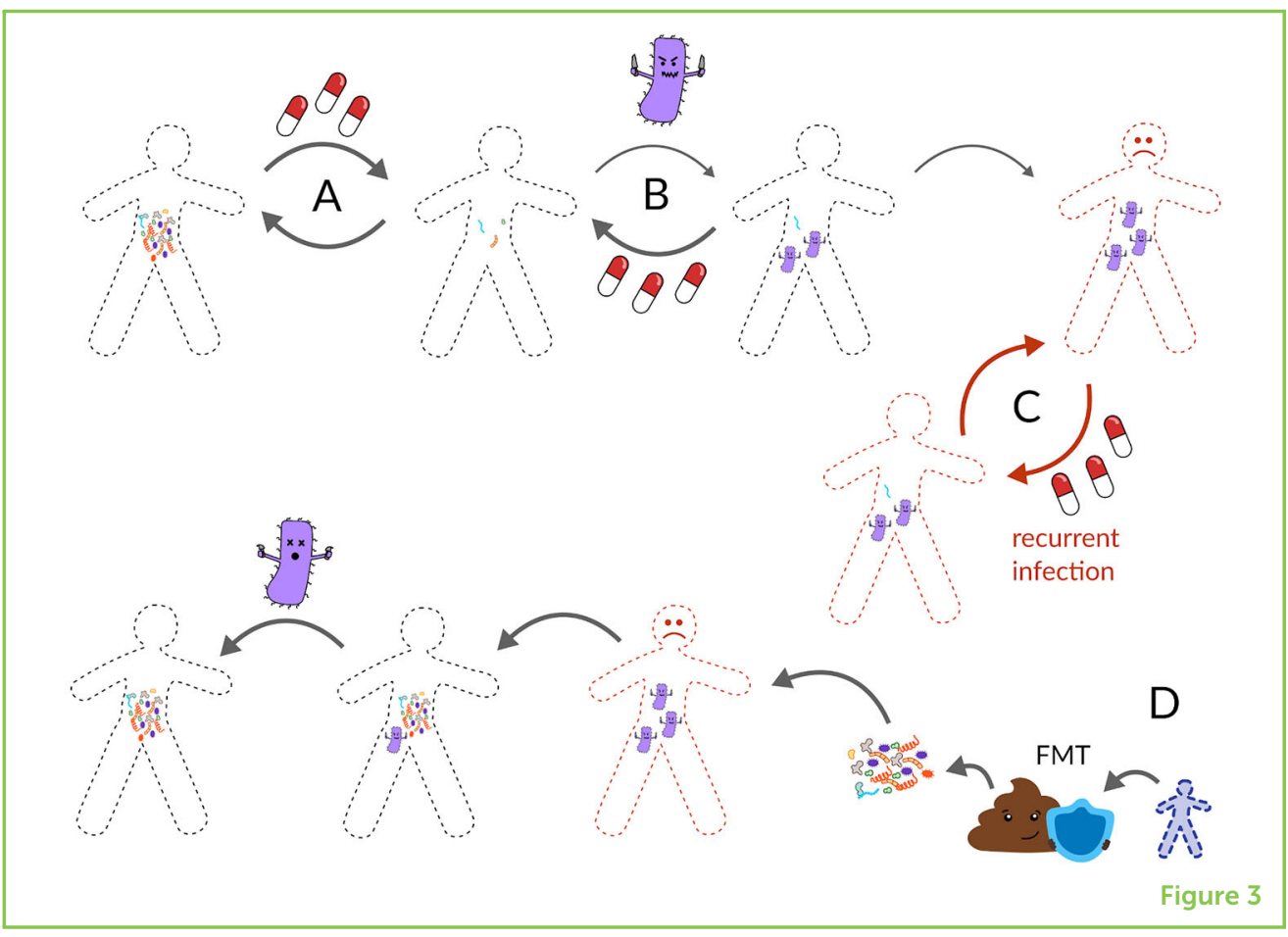

microbiota looks like, we can often recognize an unhealthy microbiota when we see one. For example, eating spoiled food can introduce pathogens into the gut, leading to an upset stomach and diarrhea. Most of us have taken antibiotics at some point in our lives to get rid of the bacteria that make us sick. However, antibiotics cannot tell the difference between "good" and "bad" microbes. Each time we take antibiotics, it is like having a fire burn through our gut, damaging our internal ecology. Just like a forest after a fire, the gut ecosystem usually bounces back from antibiotic treatment. But sometimes, instead of bouncing back, weed-like microbes can take over, causing disease and preventing the good microbes from returning (Figure 2).

\section{DEADLY CLOSTRIDIOIDES DIFFICILE INFECTIONS}

Clostridioides difficile is a weed-like microbe known as an opportunistic pathogen. Opportunistic gut pathogens are microbes that do not normally cause harm, but when the gut ecosystem is damaged these bacteria can invade and cause a problem. For example, C. difficile can sometimes live in a healthy person's gut without causing trouble-the resident gut microbiota prevents it from producing toxins and causing an infection. However, when the gut ecology is damaged, like after taking a round of antibiotics, this weed-like pathogen can take over and cause severe diarrhea (Figure 3A) [5]. According to a report by the Center for Disease Control (CDC) in 2011, C. difficile causes about 500,000 infections and kills around 15,000 people each year in the United States, making it one of the most important diseases on the CDC's prevention list [5]. C. difficile tends to infect older 
FECAL MICROBIOTA TRANSPLANT (FMT)

A procedure in which poop from a healthy donor is transplanted into the colon of a sick patient.

\section{AUTOLOGOUS}

Obtained from the same individual.

\section{HETEROLOGOUS}

Obtained from a different individual.

1 https://www.openbi ome.org/about-fmt

2 https://www.openbio me.org/stool-donation adults with weakened immunity or people who have recently been sick or taken antibiotics. About $70 \%$ of C. difficile infections can be successfully treated with the antibiotic vancomycin (Figure 3B). However, in $20-35 \%$ of cases, the infection returns after vancomycin treatment [6]. These recurrent $C$. difficile infections are highly resistant to further antibiotic treatment, leading to endless cycles of antibiotic treatment and infection recurrence, which can eventually result in patient death (Figure 3C) [7].

\section{POOP TRANSPLANTS}

Thinking back to our forest metaphor, imagine the ecosystem has burned down, been stripped of its native vegetation, and is now overgrown by weeds. One way to return the forest to its original state would be to cut down all the weeds and transplant flora and fauna from a nearby patch of unburned forest. Poop transplants, known as fecal microbiota transplants (FMTs), work in a similar way. First, a patient is given a dose of antibiotics to reduce the abundance of $C$. difficile and then the patient is given a dose of healthy poop from a poop donor (Figure 3D). Traditionally, poop transplants were administered by enema or through a tube going through the nose, down the throat, and into the gut, but now patients can swallow pills containing frozen or freeze-dried poop.

While the exact mechanisms are not completely understood, transplanted microbiota from a healthy person's gut regain control of the ecosystem and push $C$. difficile out. FMTs can be either autologous (healthy poop from yourself, collected before you were sick) or heterologous (healthy poop from another person). As gross as they sound, these poop transplants have been shown to be $80-90 \%$ effective in resolving recurrent $C$. difficile infections ${ }^{1}$ and have been used to cure tens-of-thousands of patients in the U.S. Thus, FMT is a life-saving option for people with recurrent $C$. difficile.

\section{SAFETY FIRST}

FMTs are highly effective and the Food and Drug Administration (FDA) has temporarily approved them as treatments for recurrent $C$. difficile infections. However, it is important to be extremely careful when choosing healthy poop donors. Currently, companies that make FMT material must test poop donors for most known human pathogens and for antibiotic-resistant bacteria. Poop donors are also subject to strict screening based on their lifestyle, travel, and medical history. Only the very best poop is acceptable, and approved donors can make up to $\$ 40$ per poop donation ${ }^{2}$. Most healthy people carry one or more opportunistic pathogens in their gut, which are harmless when the gut ecosystem is healthy, but these organisms could cause trouble if they were transferred into a sick patient. 
3 http://www.fda.gov /news-events/fda-brief /fda-brief-fda-warns -about-potential-risk -serious-infections -caused-multi-drug -resistant-organisms

4 https://www. openbiome.org /press-releases /2020/3/12/ openbiomeannouncesenhanced-donor -screeningprotocolsfollowing-fda-alert

Recent events have shown how important donor screening is. Over the last couple years, eight patients have developed infections from pathogens that were passed to them through FMT, leading to the deaths of three patients ${ }^{3}$. Some of these patients had undergone bone marrow transplants, and their immune systems were extremely weak, making them especially susceptible to opportunistic pathogens. In one case, the poop donors were not screened using the most up-to-date regulations [8]. In another case, proper screening was done but this screening was still not sufficient to catch certain pathogens that caused problems in six patients, leading to updated screening criteria $^{4}$. Thus, it is crucial that FMT material be prepared in an FDA-regulated lab with strict procedures in place. Screening should be continuously updated in response to new pathogens like SARS-CoV-2, and FMT procedures should always be performed by certified doctors. FMTs should never be performed at home! Furthermore, long-term risks from FMTs are not well-known yet, because these procedures have not been in use for very long. Despite the potential risks of FMT, properly-screened donor material is currently the most effective treatment for recurrent $C$. difficile infections, with very few adverse effects after tens-of-thousands of treatments across the U.S.

\section{FMT: THE CURRENT BEST OPTION FOR RECURRENT C. DIFFICILE}

Despite FMT's success, it remains a controversial treatment. Poop is highly variable between donors and cannot be controlled or regulated under the same rigorous standards that the FDA applies to other drugs. To solve this problem, many biotechnology companies are in a race to assemble artificial microbial communities that can be reproducibly manufactured under strict conditions, and which mimic the effects of natural human poop in treating recurrent $C$. difficile infections. So far, none of these synthetic FMT alternatives have proven to be as effective as FMTs. The major difficulty with developing an alternative to FMTs is our lack of detailed understanding of exactly how FMTs work. While there is hope that someday soon a simpler treatment will be available, for now, FMTs are still the best option for fighting the deadly scourge of recurrent $C$. difficile infections.

\section{ACKNOWLEDGMENTS}

SMG, SP, and CD were supported by a Washington Research Foundation Distinguished Investigator Award and by startup funds from the Institute for Systems Biology. BH and SS were part of the STEAM Towards a Healthier World Ambassador program, which was funded by gifts from Dee Dickinson, Douglas Howe, The Dean Witter Foundation, and supported by the Institute for Systems Biology. 


\section{REFERENCES}

1. Goffau, M. C. de, Lager, S., Sovio, U., Gaccioli, F., Cook, E., Peacock, S. J., et al. 2019. Human placenta has no microbiome but can contain potential pathogens. Nature 572:329-34. doi: 10.1038/s41586-019-1451-5

2. Rodríguez, J. M., Murphy, K., Stanton, C., Ross, R. P., Kober, O. I., Juge, N., et al. 2015. The composition of the gut microbiota throughout life, with an emphasis on early life. Microb. Ecol. Health Dis. 26:26050. doi: 10.3402/mehd.v26.26050

3. Johnson, K. V. A., and Foster, K. R. 2018. Why does the microbiome affect behaviour? Nat. Rev. Microbiol. 16:647-55. doi: 10.1038/s41579-018-0014-3

4. McBurney, M. I., Davis, C., Fraser, C. M., Schneeman, B. O., Huttenhower, C., Verbeke, K., et al. Establishing what constitutes a healthy human gut microbiome: state of the science, regulatory considerations, and future directions. J. Nutr. 149:1882-95. doi: 10.1093/jn/nxz154

5. CDC. 2016. CDC Press Releases. Available online at: https://www.cdc.gov/ media/releases/2015/p0225-clostridium-difficile.html (accessed October 31, 2019).

6. Hopkins, R. J., and Wilson, R. B. 2018. Treatment of recurrent Clostridium difficile colitis: a narrative review. Gastroenterol. Rep. 6:21-8. doi: 10.1093/gastro/ gox041

7. Ofosu, A. 2016. Clostridium difficile infection: a review of current and emerging therapies. Ann. Gastroenterol. Q. Publ. Hell. Soc. Gastroenterol. 29:147-54. doi: 10.20524/aog.2016.0006

8. DeFilipp, Z., Bloom, P. P., Torres Soto, M., Mansour, M. K., Sater, M. R. A., Huntley, M. H., et al. 2019. Drug-resistant E. coli bacteremia transmitted by fecal microbiota transplant. N. Engl. J. Med. 381:2043-50. doi: 10.1056/NEJMoa19 10437

SUBMITTED: 10 June 2020; ACCEPTED: 11 January 2021; PUBLISHED ONLINE: 05 February 2021.

EDITED BY: Bahtiyar Yilmaz, Bern University Hospital, Switzerland

CITATION: Patwardhan S, Diener C, Swegle S, Howsmon B and Gibbons S (2021) What Are Poop Transplants and How Do They Work? Front. Young Minds 9:571389. doi: 10.3389/frym.2021.571389

CONFLICT OF INTEREST: The authors declare that the research was conducted in the absence of any commercial or financial relationships that could be construed as a potential conflict of interest.

COPYRIGHT @ 2021 Patwardhan, Diener, Swegle, Howsmon and Gibbons. This is an open-access article distributed under the terms of the Creative Commons Attribution License (CC BY). The use, distribution or reproduction in other forums is permitted, provided the original author(s) and the copyright owner(s) are credited and that the original publication in this journal is cited, in accordance with accepted academic practice. No use, distribution or reproduction is permitted which does not comply with these terms. 



\section{YOUNG REVIEWERS}

\section{JADA, AGE: 14}

Hi! My name is Jada from Atlanta, GA. In my free time, I like to draw/sketch, listen to music, write short stories, and watch an array of movies. I play lacrosse, and I swam for about 5 years. When I become older, I want to be a Cosmetic Plastic Surgeon because I want to make all of my patients proud of their bodies and not insecure about themselves. Helping others is one of my motivations in life!!!

\section{JOSHUA, AGE: 14}

I am a rising ninth grader and I live in Atlanta, Georgia. During the academic school year I participate in many programs including the Academic team and the Lacrosse team. When I am not studying or at school I love to read books and play lacrosse. I am happy to be a part of this program because I enjoy science, and I am happy that my feedback is so important in helping people publish their articles.

\section{REEYA, AGE: 15}

My name is Reeya and I am a soon-to-be A-level student who is passionate about Biology. In my spare time, I love to read crime novels, a particular favorite is James Patterson's "Along Came a Spider." Furthermore, I like to watch TED Talks and listen to podcasts, such as the BBC's Law in Action podcast. I really like to travel, especially to countries in Europe. In the future, I aspire to study law or economics as I have an interest in social sciences.

\section{AUTHORS}

\section{SUSHMITA PATWARDHAN}

Sushmita is a former Post-doctoral Fellow at the Institute for Systems Biology (ISB). Currently, she is a Medical Writer at PRECISIONscientia, a medical communications agency. She enjoys science writing and science communication.

\section{CHRISTIAN DIENER}

Christian is a Research Scientist at the Institute for Systems Biology (ISB) in Seattle, Washington. He is studying how the gut microbiota provides us with nutrients and other molecules and how that can protect us from getting sick.

\section{STEPHANIE SWEGLE}

Stephanie just graduated from Seattle Prep High School and is going to attend Notre Dame in August. She is an intern in the Systems Education Experience (SEE) team at the Institute for Systems Biology (ISB) in Seattle, Washington. She is passionate about finding creative and innovative ways to solve environmental and health problems and wants to become a bioengineer. 


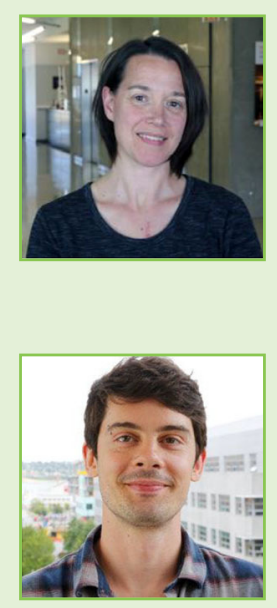

\section{BECKY HOWSMON}

Becky is a Project Manager with the Systems Education Experience (SEE) program at the Institute for Systems Biology (ISB) in Seattle, Washington. She is developing high school curriculum focused on systems medicine. She is passionate about creating opportunities that allow every student to explore their interests and realize their potential.

\section{SEAN M. GIBBONS}

Sean is an Assistant Professor at the Institute for Systems Biology (ISB) in Seattle, Washington. His lab studies the ecology and evolution of microbial communities. In particular, he is interested in how the gut microbiota influence human health and disease. *sgibbons@isbscience.org 